\title{
Association between handgun purchase and mortality from firearm injury
}

\author{
K M Grassel, G J Wintemute, M A Wright, M P Romero
}

Injury Prevention 2003;9:48-52

\begin{abstract}
Objective: To determine the association between mortality from violent or firearm related injury and previous handgun purchase.

Methods: Case-control study of 213466 Californians ages 21 and older who died in 1998; cases were the 4728 violent or firearm related injury deaths, with subsets by specific cause and means of death, and controls were the 208738 non-injury deaths. The exposure of interest was the purchase of a handgun during 1996-98. The main outcome measure was the odds ratio for handgun purchase, adjusted for age, sex, race, education, and marital status.

Results: Handgun purchase was more common among persons dying from suicide (odds ratio (OR) 6.8; $95 \%$ confidence interval (CI) 5.7 to 8.1 ) or homicide (OR $2.4,95 \% \mathrm{Cl} 1.6$ to 3.7 ), and particularly among those dying from gun suicide (OR $12.5 ; 95 \% \mathrm{Cl} 10.4$ to 15.0 ) or gun homicide (OR 3.3 ; $95 \% \mathrm{Cl} 2.1$ to 5.3$)$, than among controls. No such differences were seen for non-gun suicide or homicide. Among women, those dying from gun suicide were much more likely than controls to have purchased a handgun (OR 109.8; $95 \% \mathrm{Cl} 61.6$ to 195.7). Handgun purchasers accounted for less than $1 \%$ of the study population but $2.4 \%$ of gun homicides, $14.2 \%$ of gun suicides, and $16.7 \%$ of unintentional gun deaths. Gun suicide made up $18.9 \%$ of deaths among purchasers but only $0.6 \%$ of deaths among non-purchasers.
\end{abstract}

Conclusion: Among adults who died in California in 1998, those dying from violence were more likely than those dying from non-injury causes to have purchased a handgun.
A lthough firearm mortality rates in the United States have decreased since 1993, firearms accounted for 28663 deaths in 2000 and ranked 11th among all causes of death. ${ }^{1}$ Gun homicide rates have fallen dramatically in the last decade, ${ }^{2}$ but gun suicide rates have seen little change. In 2000 there were 16586 gun suicides among persons age 21 and older, outnumbering the 10801 gun homicides by $54 \%{ }^{1}$

Case-control studies find that gun availability increases risk of homicide, ${ }^{3-6}$ while one cohort study finds this to be true for women, but not for men. ${ }^{7}$ With one exception, ${ }^{8}$ studies of suicide have consistently shown that the risk of suicide increases when a firearm is available. ${ }^{35-79}$ The majority of these studies, however, inferred a passive exposure to a handgun (for example, a handgun present in the home). Little is known about the relationship between handgun purchase itself-the conscious decision to undergo a sustained close exposure to firearms - and subsequent risk of violent or firearm related mortality.

In a cohort study of handgun purchasers in California in 1991, the purchase of a handgun was associated with a substantial increase in risk of firearm suicide that was present within a week of purchase and persisted for at least six years. ${ }^{7}$ The continuing decline in overall rates of firearm related death since that study was conducted may have affected the association between handgun purchase and mortality. In addition, that earlier study left several important questions unanswered: Among those who die from gun violence, particularly suicide, what proportion have recently purchased a handgun? Are very recent handgun purchasers most likely to die from violence, especially firearm related violence?

To answer these questions, we performed a case-control study of all people age 21 and older who died in California in 1998. Our hypothesis was that people dying from violence, and especially firearm related violence, were more likely to have bought a handgun in the three years before their death than those who died from non-injury causes. We also hypothesized that those who died from violence were much more likely to have bought a handgun very recently-within one year of death-than were those who died from non-injury causes. We also compared the prevalence and ranking of deaths from violence and firearm related injury among handgun purchasers and non-purchasers.

\section{METHODS}

California's automated Death Statistical Master File contains information on all deaths that occur in the state. We used this file to identify all persons age 21 and older who died in California in $1998(n=221317)$. The file provided information on sex, age, race, marital status, years of education, date of birth, date of death, and cause of death (International Classification of Diseases, 9th revision, codes including four digit E codes). ${ }^{10}$ We used California's state handgun purchase data from 1996-98 to identify handgun purchasers. The handgun purchase data contain records of all legal handgun purchases made from licensed California firearm retailers. Handgun sales between private parties would be included in these data if they were conducted legally, as California law requires all such sales to go through a licensed retailer. Any private sales or transfers not going through a licensed retailer would not appear in the purchase data.

The mortality file was joined with the purchase data by matching on last name and date of birth. Apparent matches were manually reviewed and verified using additional data such as sex, place of birth, and middle name. Subjects in the mortality file with no match in the purchase data were considered not to have purchased a handgun within three years of death

Abbreviations: $\mathrm{Cl}$, confidence interval; $\mathrm{OR}$, odds ratio 
We used a case-control study design, rather than a proportional mortality design, to enhance the validity of the study. ${ }^{11} 12$ As recommended by Rothman and Greenland ${ }^{11}$ and Miettinen and Wang, ${ }^{12}$ cases in such a design are persons who died from the causes of death that are being investigated. In selecting controls, it is then important to exclude persons for whose causes of death an association with the exposure of interest is "known, suspected, or merely plausible" (Rothman and Greenland, p $77^{11}$ ).

In applying that principle to selecting controls for this study, we noted that firearm ownership generally, ${ }^{13}$ the ownership of semiautomatic and automatic firearms specifically, ${ }^{14}$ and carrying a firearm on one's person ${ }^{15}$ are all associated with abusive consumption of alcohol. As alcohol abuse is one of the most important risk factors for death from unintentional injury, we considered it likely that handgun purchase is associated, though perhaps indirectly, with risk for an unintentional injury death. We therefore excluded from our control population persons who died from unintentional injuries, such as motor vehicle crashes and falls $(n=7617)$. We also excluded persons who died from injuries of undetermined intent $(n=185)$, legal intervention $(n=47)$, and injuries resulting from operations of war $(n=2)$.

The main outcome measure for the study is the exposure odds ratio: the odds of having purchased a handgun before death among cases relative to controls. We used logistic regression to calculate odds ratios and 95\% confidence intervals, which we adjusted for age, sex, race, education, and marital status. Age was treated as a categorical variable (table 1). We developed multiple models to compare subsets of our case population with the control group. These subsets included persons who died of any intentional violence, homicide, suicide, and unintentional firearm deaths. We stratified subsets related to violence by whether or not deaths were firearm related. The control population remained constant across all comparisons.

\section{RESULTS}

A total of 213466 people age 21 and older who died in California in 1998 made up our study population: 4728 cases died from a violent or firearm related injury $(2.2 \%$ of the study population), and 208738 controls died from non-injury causes $(97.8 \%$ of the study population) (table 1$)$. The 1162 persons $(0.5 \%$ of the study population) who were known to have purchased a handgun between 1996 and 1998 were considered to have sustained the exposure of interest.

Men accounted for $79.3 \%$ of cases but only $48.8 \%$ of controls (table 1). Those who died from violent or firearm related injury were younger (mean age 44.6) than those who died from non-injury causes (mean age 74.7). There were much higher proportions of Hispanics and black people and a lower proportion of white people among cases compared with controls. There was little difference in educational history between the two groups, but those dying from violent or firearm related injury were more likely to be single or divorced, and less likely to be married or widowed, than were those dying from non-injury causes.

Persons who died from intentional violence were more likely than those who died from non-injury causes to have purchased a handgun (odds ratio (OR) 5.7; 95\% confidence interval (CI) 4.8 to 6.8 ) (table 2). This was also true for the subsets of cases dying from suicide (OR 6.8; 95\% CI 5.7 to 8.1 ) and homicide (OR 2.4; $95 \%$ CI 1.6 to 3.7 ), and particularly for those dying from gun suicide (OR $12.5 ; 95 \%$ CI 10.4 to 15.0 ) or gun homicide (OR 3.3; 95\% CI 2.1 to 5.3 ). No such difference was seen for cases dying from non-gun suicide or homicide.

Very recent handgun purchase, defined as purchase within one year of death, was strongly associated with violent or firearm related injury death (table 3 ). This was again the case for both suicide (OR 12.5; 95\% CI 10.0 to 15.6) and homicide (OR 3.9; 95\% CI 2.2 to 6.8), and particularly gun suicide (OR $22.7 ; 95 \%$ CI 18.2 to 28.4 ) and gun homicide (OR 5.8; 95\% CI 3.1 to 10.8 )
Table 1 Characteristics of Californians age 21 and older who died in 1998; results are number (\%)

\begin{tabular}{|c|c|c|}
\hline Characteristics & $\begin{array}{l}\text { Violent injury death } \\
(n=4728)\end{array}$ & $\begin{array}{l}\text { Non-injury death } \\
(n=208738)\end{array}$ \\
\hline \multicolumn{3}{|l|}{ Purchaser* } \\
\hline Yes & $275(5.8)$ & $887(0.4)$ \\
\hline No & 4453 (94.2) & 207851 (99.6) \\
\hline \multicolumn{3}{|l|}{ Recent purchasert } \\
\hline Yes & $200(4.2)$ & $369(0.2)$ \\
\hline No & $4528(95.8)$ & $208369(99.8)$ \\
\hline \multicolumn{3}{|r|}{2000018.018} \\
\hline Male & 3748 (79.3) & $101864(48.8)$ \\
\hline Female & $980(20.7)$ & $106874(51.2)$ \\
\hline \multicolumn{3}{|l|}{ Age } \\
\hline $21-24$ & $553(11.7)$ & $410(0.2)$ \\
\hline $25-34$ & $1113(23.5)$ & $2311(1.1)$ \\
\hline $35-44$ & 1097 (23.2) & $6800(3.3)$ \\
\hline $45-54$ & 744 (15.7) & $13473(6.5)$ \\
\hline $55-64$ & $417(8.8)$ & $21394(10.2)$ \\
\hline $65-74$ & $340(7.2)$ & 42075 (20.2) \\
\hline$\geqslant 75$ & $464(9.8)$ & 122275 (58.6) \\
\hline \multicolumn{3}{|l|}{ Race } \\
\hline White & 2788 (59.0) & 158063 (75.7) \\
\hline Hispanic & $1003(21.2)$ & $21803(10.4)$ \\
\hline Black & $578(12.2)$ & $15563(7.5)$ \\
\hline Asian & $283(6.0)$ & $11483(5.5)$ \\
\hline Other, unknown & $76(1.6)$ & $1826(0.9)$ \\
\hline \multicolumn{3}{|l|}{ Years of education } \\
\hline$<12$ & 1079 (22.8) & $53946(25.8)$ \\
\hline 12 & 1792 (37.9) & $79490(38.1)$ \\
\hline $13-15$ & $884(18.7)$ & 35259 (16.9) \\
\hline 16 & $503(10.6)$ & $20689(9.9)$ \\
\hline$\geqslant 17$ & $314(6.6)$ & $12729(6.1)$ \\
\hline Unknown & $156(3.3)$ & $6625(3.2)$ \\
\hline \multicolumn{3}{|l|}{ Marital status } \\
\hline Married & 1705 (36.1) & 86231 (41.3) \\
\hline Single & $1718(36.3)$ & $16326(7.8)$ \\
\hline Divorced & $833(17.6)$ & $25976(12.4)$ \\
\hline Widowed & $381(8.1)$ & 78623 (37.7) \\
\hline Unknown & $91(1.9)$ & $1582(0.8)$ \\
\hline
\end{tabular}

The association between handgun purchase and violent death was stronger among women than in the study population as a whole (table 4 ). In particular, women who died from gun suicide were much more likely to have purchased a handgun than women who died from non-injury causes (OR 109.8; $95 \%$ CI 61.6 to 195.7 ). Since $79.3 \%$ (3748 of 4728 ) of the cases were men, odds ratios for men were very similar to those for all cases and are not shown separately.

Almost 22\% (252 of 1162) of deaths among handgun purchasers were firearm related. Gun suicide accounted for $18.9 \%$ of deaths among handgun purchasers and $0.6 \%$ of deaths among non-purchasers. Gun suicide was the third leading cause of death among male handgun purchasers, accounting for $17.5 \%$ of all deaths ( 188 of 1076), but made up only $1.1 \%$ of deaths among male non-purchasers (1155 of $104536)$. Gun suicide was the leading cause of death for female purchasers and accounted for $37.2 \%$ of all deaths in that group (32 of 86 ), but accounted for only $0.2 \%$ of deaths among female non-purchasers (171 of 107768 ). Gun suicide was also the leading cause of death among persons who purchased a handgun within one year of death, accounting for $29.3 \%$ of all deaths in that population (167 of 569 ).

Handgun purchasers made up just $0.5 \%$ of our study population ( 1162 of 213466 persons ), but accounted for $5.8 \%$ of all violent deaths (275 of 4728), $7.8 \%$ of suicides (237 of 3035), and $1.9 \%$ of homicides (32 of 1657). Similarly, purchasers accounted for $14.2 \%$ of gun suicides (220 of 1546), $2.4 \%$ of gun homicides (26 of 1102), and $16.7 \%$ of unintentional gun deaths (six of 36). Of all handgun purchasers who died in $1998,48.9 \%$ ( 569 of 1162 ) bought a handgun within one year of their deaths. 
Table 2 Crude and adjusted odds ratios for handgun purchase within three years of death among Californians age 21 and older who died from selected injury causes in 1998, compared with persons who died from non-injury causes

\begin{tabular}{|c|c|c|c|c|c|}
\hline \multirow[b]{2}{*}{ Cause of death } & \multicolumn{2}{|c|}{ No exposed/No unexposed } & \multicolumn{3}{|c|}{ Odds ratios ( $95 \%$ confidence intervals) } \\
\hline & Cases & Controls & Unadjusted & Adjusted* & $\mathrm{p}$ Value \\
\hline Intentional violencet & $269 / 4423$ & $887 / 207851$ & 14.3 (12.4 to 16.4$)$ & 5.7 (4.8 to 6.8$)$ & $<0.001$ \\
\hline Any gun injury & $252 / 2432$ & $887 / 207851$ & $24.3(21.0$ to 28.1$)$ & 10.2 (8.5 to 12.2 ) & $<0.001$ \\
\hline Suicide & $237 / 2798$ & $887 / 207851$ & $19.8(17.1$ to 23.0$)$ & 6.8 (5.7 to 8.1$)$ & $<0.001$ \\
\hline Gun suicide & $220 / 1326$ & $887 / 207851$ & 38.9 (33.2 to 45.5$)$ & 12.5 (10.4 to 15.0$)$ & $<0.001$ \\
\hline Non-gun suicide & $17 / 1472$ & $887 / 207851$ & $2.7(1.7$ to 4.4$)$ & $0.9(0.6$ to 1.6$)$ & 0.814 \\
\hline Homicide & $32 / 1625$ & $887 / 207851$ & $4.6(3.2$ to 6.6$)$ & 2.4 (1.6 to 3.7$)$ & $<0.001$ \\
\hline Gun homicide & $26 / 1076$ & $887 / 207851$ & 5.7 (3.8 to 8.4$)$ & $3.3(2.1$ to 5.3$)$ & $<0.001$ \\
\hline Non-gun homicide & $6 / 549$ & $887 / 207851$ & 2.6 (1.1 to 5.7$)$ & $1.3(0.6$ to 2.9$)$ & 0.551 \\
\hline Gun unintentional & $6 / 30$ & $887 / 207851$ & 46.9 (19.5 to 112.9$)$ & $18.5(7.0$ to 48.6$)$ & $<0.001$ \\
\hline
\end{tabular}

*Adjusted for age, sex, race, education, and marital status.

tCombines homicide and suicide.

Table 3 Crude and adjusted odds ratios for handgun purchase within one year of death among Californians age 21 and older who died from selected injury causes in 1998, compared with persons who died from non-injury causes

\begin{tabular}{|c|c|c|c|c|c|}
\hline \multirow[b]{2}{*}{ Cause of death } & \multicolumn{2}{|c|}{ No exposed/No unexposed } & \multicolumn{2}{|c|}{ Odds ratios ( $95 \%$ confidence intervals) } & \multirow[b]{2}{*}{$\mathrm{p}$ Value } \\
\hline & Cases & Controls & Unadjusted & Adjusted* & \\
\hline Intentional violencet & $197 / 4495$ & $369 / 208369$ & $24.7(20.8$ to 29.5$)$ & 10.7 (8.6 to 13.4$)$ & $<0.001$ \\
\hline Any gun injury & $185 / 2499$ & $369 / 208369$ & 41.8 (34.9 to 50.1$)$ & 19.3 (15.4 to 24.2 ) & $<0.001$ \\
\hline Suicide & $179 / 2856$ & $369 / 208369$ & $35.4(29.5$ to 42.5$)$ & 12.5 (10.0 to 15.6$)$ & $<0.001$ \\
\hline Gun suicide & $167 / 1379$ & $369 / 208369$ & $68.4(56.5$ to 82.7$)$ & 22.7 (18.2 to 28.4$)$ & $<0.001$ \\
\hline Non-gun suicide & $12 / 1477$ & $369 / 208369$ & $4.6(2.6$ to 8.2$)$ & $1.6(0.9$ to 3.0$)$ & 0.130 \\
\hline Homicide & $18 / 1639$ & $369 / 208369$ & 6.2 (3.9 to 10.0 ) & $3.9(2.2$ to 6.8$)$ & $<0.001$ \\
\hline Gun homicide & $15 / 1087$ & $369 / 208369$ & 7.8 (4.6 to 13.1$)$ & 5.8 (3.1 to 10.8$)$ & $<0.001$ \\
\hline Non-gun homicide & $3 / 552$ & $369 / 208369$ & 3.1 (1.0 to 9.6$)$ & $1.8(0.6$ to 5.9$)$ & 0.308 \\
\hline Gun unintentional & $3 / 33$ & $369 / 208369$ & $51.3(15.7$ to 168.1$)$ & 19.6 (5.4 to 70.5$)$ & $<0.001$ \\
\hline
\end{tabular}

*Adjusted for age, sex, race, education, and marital status.

tCombines homicide and suicide.

Table 4 Crude and adjusted odds ratios for handgun purchase within three years of death among female Californians age 21 and older who died from selected injury causes in 1998, compared with women who died from non-injury causes

\begin{tabular}{|c|c|c|c|c|c|}
\hline \multirow[b]{2}{*}{ Cause of death } & \multicolumn{2}{|c|}{ No exposed/No unexposed } & \multicolumn{2}{|c|}{ Odds ratios ( $95 \%$ confidence intervals) } & \multirow[b]{2}{*}{ p Value } \\
\hline & Cases & Controls & Unadjusted & Adjusted* & \\
\hline Intentional violencet & $37 / 942$ & $49 / 106825$ & $85.6(55.6$ to 131.9$)$ & $26.2(15.0$ to 45.8$)$ & $<0.001$ \\
\hline Any gun injury & $32 / 323$ & $49 / 106825$ & 216.0 (136.5 to 341.7$)$ & 73.2 (41.0 to 130.7$)$ & $<0.001$ \\
\hline Suicide & $36 / 635$ & $49 / 106825$ & 123.6 (79.8 to 191.4$)$ & 33.9 (19.3 to 59.3$)$ & $<0.001$ \\
\hline Gun suicide & $32 / 171$ & $49 / 106825$ & 408.0 (255.0 to 652.8 ) & $109.8(61.6$ to 195.7$)$ & $<0.001$ \\
\hline Non-gun suicide & $4 / 464$ & $49 / 106825$ & 18.8 (6.8 to 52.3 ) & 4.6 (1.5 to 14.5$)$ & 0.009 \\
\hline Homicide & $1 / 307$ & $49 / 106825$ & $7.1(1.0$ to 51.6$)$ & 2.5 (0.3 to 20.1$)$ & 0.400 \\
\hline Gun homicide & $0 / 151$ & $49 / 106825$ & - & - & - \\
\hline Non-gun homicide & $1 / 156$ & $49 / 106825$ & $14.0(1.9$ to 101.8$)$ & $4.0(0.5$ to 32.8$)$ & 0.195 \\
\hline Gun unintentional & $0 / 1$ & $49 / 106825$ & - & - & - \\
\hline
\end{tabular}

*Adjusted for age, race, education, and marital status.

tCombines homicide and suicide.

\section{DISCUSSION}

Among Californians who died in 1998, those whose deaths resulted from violence or firearm related injury were more likely than those who died from non-injury causes to have purchased a handgun between 1996 and 1998. While this association was strongest among persons dying from suicide, there was no evidence that the purchase of a handgun produced a protective effect against homicide; homicide victims were also more likely to have purchased a handgun than those dying from non-injury causes. Over one fifth of deaths among handgun purchasers, but just $1.1 \%$ of deaths among non-purchasers, were from gun related injury-an increase that was attributable almost entirely to an increase in gun suicide. Handgun purchasers constituted just $0.5 \%$ of our study population, but they committed $14.2 \%$ of gun suicides.
Among women, the association between violent death and handgun purchase was remarkably strong, again due largely to gun suicide. Although the number of female purchasers in our study population was small, these results should not be dismissed. Handgun manufacturers have recently increased the marketing of guns to women by touting the protection handguns may provide them. ${ }^{16}$ Our findings show, however, that women who died from violence were more likely, not less, to have purchased a handgun within the three years before death.

For three reasons, our findings probably underestimate the association between violent or firearm related death and prior purchase of a handgun. First, although our non-purchasers had not bought a handgun from a licensed California gun retailer within three years before their deaths, they could have 
done so earlier. They could also have recently purchased a handgun from a source other than a licensed retailer without producing a record of the transaction. This has been illegal in California since 1991, but we believe it occurs frequently: perhaps $40 \%$ of all transfers of firearms are between private parties, ${ }^{17}{ }^{18}$ but less than $10 \%$ of sales records forwarded to the California Department of Justice are for such private party sales (unpublished data on file with the authors). Second, non-purchasers could be passively exposed to guns. Some 35\% to $40 \%$ of all households in the United States have a gun, and as many as $25 \%$ have a handgun. ${ }^{18-21}$ Even passive exposure appears to increase the risk of a gun related death and therefore would increase the risk of dying by gun violence in our non-purchasing population..$^{4-69}$ Our odds ratios are therefore probably lower than would be observed if handgun exposure, whether by personal acquisition or passively, could be measured perfectly.

Third, we are unable to eliminate completely from our control population persons dying from causes of death that are "plausibly" (Rothman and Greenland, p $77^{11}$ ) related to our exposure of interest. Alcohol abuse, for which an association with both gun use and unintentional injury death led us to exclude injury deaths from our control group, is also related to death from some forms of cancer and cardiovascular disease and other causes-though the attributable risk is both less in absolute terms and not as predominant as it is for unintentional injury. Handgun purchase may be indirectly associated with many causes of death if it is associated with other common behavioral risk factors; including these causes of death in our control population is another source of conservative bias in our estimates of association.

Our results are subject to other limitations. Since all members of our study population died, we could not estimate the actual risk of dying from gun related causes. We do not know if the gun deaths of the purchasers in our study population involved the handguns they bought between 1996 and 1998, nor do we know if any purchasers resold their guns before death and were no longer exposed. The study population does not include persons less than 21 years of age, because they are prohibited from purchasing a handgun. We measured the effect a handgun purchase had on causes of death among purchasers who died in 1998, not on other members of their households.

We also did not have data for attributes such as mental illness, isolation, alcohol and other drug abuse, exposure to violence, and a prior criminal history, that earlier studies have found to have a relationship, independent of household gun ownership, to risk for homicide or suicide. ${ }^{4-6}$ It is important to note that those studies used live controls. In this study, where all subjects died and case-control assignment was made on cause of death, not vital status, the relationship between such attributes and the primary exposure and outcome of interest could be quite different.

Because our data allowed us to measure the effects of an individual's decision to assume the risks associated with handgun ownership, the results of this study differ from those of past case-control studies. With one exception, ${ }^{3}$ previous studies only measured the risk of a passive exposure to a handgun present in the household. ${ }^{4-69}$ In addition, this study focused on recent exposure to a handgun, whereas exposure in all other studies but one ${ }^{3}$ was of unknown duration.

Our findings document a very strong association between handgun purchase and subsequent gun suicide. There are few evidence based solutions to the problem of suicide. It would, for example, be difficult to screen potential gun buyers for suicide risk factors. ${ }^{7}$ General restrictions on handgun ownership, on the other hand, have been found to reduce gun suicide rates without an increase in suicide by other means. ${ }^{22}$ Since those who die from gun suicide are likely to have been recent handgun purchasers, it is possible that an extended waiting period could have a "cooling off " effect. ${ }^{23-25}$ It is also possible,

\section{Key points}

- Among adults dying in California in 1998, a handgun purchase during 1996-98 was more common among persons dying from suicide (OR 6.8), gun suicide (OR 12.5), homicide (OR 2.4), and gun homicide (OR 3.3) than among those dying from non-injury causes.

- Among women, handgun purchase was much more common among those dying from suicide (OR 33.9) and gun suicide (OR 109.8). Gun suicide accounted for $37.2 \%$ of all deaths among women who purchased handguns.

Persons who bought a handgun during 1996-98 made up $0.5 \%$ of those who died in 1998 , but accounted for $5.8 \%$ of all violent deaths, $2.4 \%$ of gun homicides, $14.2 \%$ of gun suicides, and $16.7 \%$ of unintentional gun deaths.

- Gun suicide accounted for $18.9 \%$ of deaths among handgun purchasers and $0.6 \%$ of deaths among non-purchasers.

however, that this "cooling off " period would only delay suicides, not prevent them. Temporary prohibitions on gun purchase by persons who have been involuntarily hospitalized for mental health reasons, a policy that was recently adopted in California, may be of some benefit.

\section{ACKNOWLEDGEMENTS}

The authors are grateful to the California Departments of Justice and Health Services for supplying the data used in this study, and to Barbara Claire, VPRP's program administrator; Dr Christiana Drake, Melissa Garcia, and Vanessa McHenry for able technical support.

This research was supported by grants from the Joyce Foundation and The David and Lucile Packard Foundation (1999-8827).

\section{Authors' affiliations}

K M Grassel, G J Wintemute, M A Wright, M P Romero, Violence

Prevention Research Program, University of California, Davis

\section{REFERENCES}

1 Minino AM, Arias E, Kochanek KD, et al. Deaths: final data for 2000 National Vital Statistics Reports 2002;50(15):1-120.

2 Blumstein A. Disaggregating the violence trends. In: Blumstein A, Wallman J, eds. The crime drop in America. New York, NY: Cambridge University Press, 2000: 13-44.

3 Cummings P, Koepsell TD, Grossman DC, et al. The association between the purchase of a handgun and homicide or suicide. Am J Public Health 1997;87:974-8.

4 Kellermann AL, Rivara FP, Rushforth NB, et al. Gun ownership as a risk factor for homicide in the home. N Engl J Med 1993;329:1084-91.

5 Kellermann AL, Somes G, Rivara FP, et al. Injuries and deaths due to firearms in the home. J Trauma 1998;45:263-7.

6 Bailey JE, Kellermann AL, Somes GW, et al. Risk factors for violent death of women in the home. Arch Intern Med 1997;157:777-82.

7 Wintemute GJ, Parham CA, Beaumont JJ, et al. Mortality among recent purchasers of handguns. N Engl J Med 1999;341:1583-9.

8 Beautrais AL, Joyce PR, Mulder R. Access to firearms and the risk of suicide: a case control study. Aust N Z J Psychiatry 1996:30:741-8.

9 Kellermann AL, Rivara FP, Somes G, et al. Suicide in the home in Kellermann AL, Rivara FP, Somes G, et al. Suicide in the home
relation to gun ownership. N Engl J Med 1992;327:467-72.

10 World Health Organization. Internal classification of diseases, 9th revision (ICD-9). Geneva, Switzerland: World Health Organization, 1978.

11 Rothman KJ, Greenland S. Types of epidemiologic study. In: Rothman KJ, Greenland S, eds. Modern epidemiology. 2nd Ed. Philadelphia, PA: Lippincott-Raven, 1998: 67-78.

12 Miettinen OS, Wang J-D. An alternative to the proportionate mortality ratio. Am J Epidemiol 1981;114:144-8.

13 Diener E, Kerber KW. Personality characteristics of American gun-owners. J Soc Psychol 1979:107:227-38.

14 Hemenway D, Richardson E. Characteristics of automatic or semiautomatic firearm ownership in the United States. Am J Public Health 1997;87:286-8.

15 Nelson DE, Grant-Worley JA, Powell K, et al. Population estimates of household firearm storage practices and firearm carrying in Oregon. JAMA 1996;275:1744-8.

16 Diaz T. Making a killing: the business of guns in America. New York, NY: The New Press, 1999.

17 Cook PJ, Molliconi S, Cole TB. Regulating gun markets. Journal of Criminal Law and Criminology 1995;86:59-92. 
18 Cook PJ, Ludwig J. Guns in America: results of a comprehensive national survey on firearms ownership and use. Washington, DC: The Police Foundation, 1996.

19 Stennies G, Ikeda R, Leadbetter S, et al. Firearm storage practices and children in the home, United States, 1994. Arch Pediatr Adolesc Med 1999;153:586-90.

20 Senturia YD, Christoffel KK, Donovan M. Children's household exposure to guns: a pediatric practice-based survey. Pediatrics 1994;93:469-75.

21 Smith TW. 1998 national gun policy survey: research findings. Chicago, IL: National Opinion Research Center, University of Chicago, 1999.
22 Loftin C, McDowall D, Wiersema B, et al. Effects of restrictive licensing of handguns on homicide and suicide in the District of Columbia. N Engl J Med 1991;325:1615-20.

23 Cantor $\mathrm{CH}$, Slater PJ. The impact of firearm control legislation on suicide in Queensland: preliminary findings. Med J Aust 1995; 162:583-5.

24 Warner K. Firearm deaths and firearm crime after gun licensing in Tasmania. Paper presented at: Third National Outlook Symposium on Crime; 22-23 March 1999; Canberra, Australia.

25 Carrington PJ, Moyer S. Gun control and suicide in Ontario. Am J Psychiatry 1994;151:606-8.

\section{LACUNAE}

\section{Zipper slips suffered in silence}

-hey may be the tip, so to speak, of a very substantial iceberg. The 13 men and boys who have fronted

up to Queensland hospitals in the past four years with trouser-zipper injuries to the penis are probably outnumbered many times by those who bear their affliction privately.

Richard Hockey, data analyst at the Queensland Injury Surveillance Unit, reveals that "people probably try to treat themselves first". "The embarrassment factor might put you off", he said.

Mr Hockey said he was surprised to discover that trapped genitals were far and away the leading cause of clothing related injury when he analysed emergency department statistics from 1998 to 2001. It could be a subtropical issue, Mr Hockey said. "Maybe it is seasonal. In the hotter weather, anecdotally, people are going without underpants. Perhaps it is now time to return to button flies".

In total, clothes were implicated in 81 injuries, including finger dislocations from putting on or removing socks, and fractures sustained in falls during that tricky stage when one leg is in the pants and the other is trying to locate the other hole.

Dressing was a highly personal ritual, Mr Hockey said, and one, perhaps, that people did not adapt sufficiently to with their age, mobility, and health. "People keep on doing it the same way, but maybe when they are a bit older can't reach their feet as well" (from the Sydney Morning Herald. Contributed by Richard Hockey).

Mike Hayes, Injury Prevention deputy editor adds: A similar cause of injury to children showed up several years ago when we undertook work on clothing safety for the UK's Department of Trade and Industry. I would not describe the UK as tropical! 